\title{
PRODUÇÃO E DISPUTAS DE SENTIDO ENTRE SUJEITOS: AS CENAS DE ENUNCIAÇÃO EM SESSÕES DE MEDIAÇÃO DE CONFLITOS FAMILIARES ${ }^{1}$
}

\author{
João Benvindo de Moura ${ }^{2}$ \\ (UNIVERSIDADE FEDERAL DO PIAUÍ) \\ Patrícia Rodrigues Tomaz ${ }^{3}$ \\ (UNIVERSIDADE FEDERAL DO PIAUÍ)
}

\section{RESUMO}

A mediação de conflitos consiste na prática que visa articular os interesses de duas partes em desacordo com o objetivo de resolver determinada contenda por meio de um acordo entre elas. $O$ presente estudo trata-se de uma pesquisa qualitativa e interpretativa e tem por objetivo analisar aspectos discursivos dos sujeitos que enunciam, considerando como cena enunciativa uma sessão de mediação de conflitos. Para fundamentar a análise, lançamos mão da noção de cena enunciativa em Maingueneau (2008) em cujo interior se encontra a cena englobante, a cena genérica e a cenografia. Consideramos a sessão de mediação como cena englobante, o relato de sessões de mediação de conflitos familiares como cena genérica, num processo de enlaçamento que possibilita a construção de uma cenografia que é construída de acordo com aquilo que o discurso diz.

Palavras-chave: Cena enunciativa. Discurso. Mediação.

\section{INTRODUÇÃO}

No momento atual, fala-se muito no instituto da mediação de conflitos, enquanto fenômeno no universo jurídico, sobretudo nos operadores de direito, que buscam o acesso à tão propalada justiça para seus clientes. Sendo assim, além da jurisdição, existem outros métodos de solução de conflitos que não sejam exclusivamente oriundos da decisão proferida pelo Estado, por meio de um magistrado. São chamados de equivalentes jurisdicionais, pois prescindem da atuação de um juiz. A mediação de conflitos é um deles.

No Brasil, temos documentos que esclarecem e asseguram a mediação: a Lei 13.105/2015, do Novo Código de Processo Civil, na busca pela redução da quantidade

\footnotetext{
${ }^{1}$ Trabalho apresentado no Congresso Brasileiro Ciência e Sociedade (CBCS 2019), promovido pelo Centro Universitário Santo Agostinho, de 03 a 05 de outubro de 2019, em Teresina-PI.

${ }^{2}$ Possui Pós-doutorado em Linguística pela UFMG (2017). Professor da Graduação e Pós-graduação em Letras da UFPI. Editor da revista Form@are (PARFOR/UFPI). Fundador e atual coordenador do Núcleo de Estudos e Pesquisas em Análise do Discurso - NEPAD/UFPI. E-mail: ibenvindo@ufpi.edu.br.

${ }^{3}$ Mestranda em Linguística (UFPI). Advogada. Mediadora Extrajudicial de Conflitos. Bacharela em Direito pelo Centro de Ensino Unificado de Teresina - CEUT (2013). Especialista em Direito Civil e Processo Civil. Especialista em Mediação de Conflitos pela ESTÁCIO-TERESINA. Membro do Núcleo de Estudos e Pesquisas em Análise do Discurso da Universidade Federal do Piauí, NEPAD-UFPI. E-mail: monitorapatriciatomaz@gmail.com, patriciatomazadvocacia@gmail.com.
} 
de processos que se arrastam na Justiça, de modo que assegure o acesso à Justiça, como direito fundamental dos jurisdicionados. Temos ainda a Lei 13.140/2015, que dispõe sobre a mediação entre particulares como meio de solução de controvérsias e sobre a autocomposição de conflitos no âmbito da administração pública.

É importante esclarecer que o Novo Código de Processo Civil estabelece a conciliação, que é imposta a um terceiro imparcial a missão de tentar aproximar os interesses de ambas as partes em conflito, orientando-as na constituição de um acordo. A mediação, por sua vez, é um procedimento que oferece àqueles que estão vivenciando um conflito, geralmente decorrente de alguma relação continuada, a oportunidade e o ambiente adequados para encontrarem, juntos, uma solução para o problema. O mediador, entretanto, não pode sugerir soluções para o conflito. A sessão de mediação é um espaço para compreensão de discursos.

Assim, o estudo da Análise do Discurso de linha francesa nos possibilita a análise de elementos discursivos em sessões de mediação de conflitos permite a assimilação de elementos implícitos ou não, sendo essencial a identificação de interesses reais. Isso acontece porque, quando as pessoas se expressam em uma sessão de mediação de conflitos, estão colocando as suas posições ou interesses aparentes (verdade aparente) e, por trás destes, há os interesses reais (verdade real), em que o sujeito enunciatário quer fazer crer na verdade do seu discurso.

\section{AS CENAS DE ENUNCIAÇÃO NA MEDIAÇÃO}

Na prática da Mediação, é importante ressaltar que há regras que determinam aos sujeitos papéis estabelecidos e, ao enunciarem, submetem-se às regras que são constitutivas desse instituto jurídico. Ao se apropriar das questões referentes aos conflitos, o mediador deve estar instruído do que pode ser dito e de como o seu discurso vai dizer. Ele deve conduzir às partes a uma decisão consensual, utilizando os elementos essenciais do discurso que norteiam o procedimento, sem romper com os parâmetros legais caracterizados conforme a lei, para que as partes aceitem e acreditem no que está sendo acordado, devido a esta prática social estar inserida num lugar creditado para dizer o que diz e

Suponho que em toda sociedade, a produção do discurso é ao mesmo tempo controlada, selecionada, organizada e redistribuída por certo número de procedimentos que têm por função conjurar seus poderes 
e perigos, dominar seu acontecimento aleatório, esquivar sua pesada e temível materialidade (FOUCAULT, 2012, p. 8-9).

Assim sendo, o discurso é legitimado porque o seu exercício pressupõe um lugar de enunciação e ao enunciar o mediador deve facilitar a comunicação e o diálogo entre os mediandos, para que estes desenvolvam sua visão a respeito do conflito a fim de que cheguem a um consenso. Ao enunciar, o discurso do mediador submete-se às regras que são constitutivas dessa instituição jurídica e, certamente, haverá momentos em que o mediador deverá intervir para contribuir com o bom desenvolvimento do procedimento, aumentando as possibilidades de se alcançar um acordo. Quando enuncia, este ato de linguagem faz sentido justamente por falar desse lugar que, como um jogo, possui regras que o identificam.

Maingueneau (1997), na formação do discurso, considera a cena enunciativa e recorre à Pragmática, apenas para explicar que todo ato de fala pressupõe uma instituição, pois ao prometer, ao afirmar, ao interrogar, a linguagem está agindo de acordo com determinadas condições próprias a ela, sendo a linguagem considerada uma forma de ação. A fim de enunciar, o enunciador constrói uma cena como se estivesse num palco de teatro, em que cada sujeito assume um papel. $A A D$, aliou-se à Pragmática, imaginando a linguagem como uma forma de ação atuante em espaços institucionais. Apoiou-se ainda numa metáfora teatral, considerando a sociedade como se fosse um teatro no qual são atribuídos papéis a cada sujeito (FERREIRA, 2008).

As teorias da enunciação, próximas à Pragmática, foram estudadas e desenvolvidas na França nas décadas de 1950-1960 por Émile Benveniste e aprofundadas a partir dos anos 1970 por Antoine Culioli (DORTIER, 2010). Nosso foco de atenção está na situação de enunciação, na atividade discursiva e no ato de enunciação. De acordo com Oliveira (2011), a cena de enunciação foi primeiramente apresentada por Dominique Maingueneau como dêixis enunciativa, em sua obra Gênese dos discursos, acrescida das concepções sobre situação de comunicação propostas por Benveniste e, posteriormente, o termo foi atualizado para cenas de enunciação, ampliando não somente a sua nomenclatura, mas no desdobramento de outras cenas dependendo do ponto de vista que se assume.

Para Maingueneau (2008), as cenas de enunciação devem ser organizadas em três dimensões, denominando-as de cena englobante, cena genérica e cenografia. A 
cena englobante representa o tipo de discurso a que pertence determinado enunciado e está relacionado ao tempo e ao espaço, surgindo da necessidade de cada grupo. Está presente na sociedade em virtude da sua finalidade e para o que foi organizado, ao domínio de saber em que se insere determinada enunciação, situando as atividades discursivas nas quais os sujeitos estão condicionados. Nos possibilita identificar se um folheto pertence ao discurso religioso, político ou publicitário e o discurso jurídico, por exemplo (MAINGUENEAU, 2013).

Na mediação de conflitos, por ser um gênero do discurso jurídico, o enunciador explora os recursos expressivos da $A D$, da língua e da lei, a fim de provocar efeitos de sentidos nos sujeitos em conflito. Na cena englobante, cada gênero de discurso define seus próprios papéis. Maingueneau (2013), dá um tratamento pragmático e traz alguns exemplos, como num panfleto de propaganda política em que o candidato se dirige aos seus eleitores, a cena englobante é política; num poema, a cena englobante é a literária; de uma oração, a religiosa. Ainda que a cena englobante situe atividades discursivas, sua caracterização é incompleta para especificar as atividades verbais, que estão relacionadas à cena genérica, em suma:

Essas duas "cenas" definem conjuntamente o que poderia ser chamado quadro cênico do texto. É ele que define o espaço estável no interior do qual o enunciado adquire sentido - o espaço do tipo e do gênero do discurso (grifo do autor) (MAINGUENEAU, 2013, p.97).

A cena genérica é estabelecida pelo gênero discursivo escolhido, determinando também a forma composicional e o estilo do enunciado. No caso da mediação, temos um gênero que exige uma forma composicional longa, cuja execução dure em média de uma a duas horas, podendo acontecer em uma ou mais sessões, se necessário, que seja organizada em etapas, como: início da sessão com o acolhimento das pessoas envolvidas e uma declaração de abertura; reunião das informações acerca do conflito; identificação e resolução das questões, interesses e sentimentos entrelaçados; esclarecimento das controvérsias, disputas e registro das possíveis soluções revisando questões e interesses envolvidos, sem forçar um acordo (CNJ, 2016, p. 150-151).

A cena genérica também determina os papéis e as funções dos sujeitos envolvidos na comunicação. No caso da mediação, um enunciador assume o papel de mediador, falando para os mediandos e esclarecendo com respeito às regras, para que estejam conscientes do funcionamento de uma sessão e não percam tempo tentando 
repetir modelos já conhecidos de técnicas adversárias de resolução de conflitos. A apresentação é breve, mas deve ser feita de maneira clara, a fim de que todos conheçam e estejam conscientes, podendo ainda realizar reuniões individuais, entre o mediador e cada um dos mediandos. Estes, ao ouvirem, esperam um enunciado jurídico, mas com palavras que lhe provoquem uma reflexão, um estímulo ou simplesmente um momento de diálogo.

O estilo da mediação, ou seja, o trabalho que o enunciador realiza para relacionar a lei e o conflito, deve ser original, respeitando a particularidade de cada caso, de acordo com a questão já que se trata de um gênero jurídico. $O$ estilo também é determinado pelo gênero jurídico da mediação, que pode ser em âmbito judicial ou extrajudicial, mas sempre será jurídica. É um procedimento e, como tal, se estabelece de uma sequência de atos em direção a um consenso. Embora não seja um procedimento inflexível, segue determinado ritual, em que várias etapas precisam ser cumpridas.

Na mediação, o mediador no papel de enunciador deve demonstrar simpatia, ser cordial, principalmente imparcial, para validar sua enunciação frente aos coenunciadores. Como a cena englobante da mediação é a jurídica, a discrição e a confidencialidade são imprescindíveis, o que permite construir uma imagem de seriedade do mediador ter e o controle da enunciação, suscitando deste público a atenção, o entendimento e a adesão ao que é proposto, criando um ambiente propício para que os envolvidos falem à vontade e apresentem suas dificuldades. Diante disso, analisar as cenas de enunciação, comparando o discurso ao escolher as marcas linguísticas, os constitutivos deste dizer, estimular com perguntas que não possam ser respondidas com monossílabas, levando em consideração os sujeitos da cena de enunciação, responsáveis pelo dizer.

Ainda com relação às cenas de enunciação, compreendemos que as cenas genéricas não são suficientes para dar conta da singularidade de um texto, por exemplo. Se considerarmos o texto como um palco, em que os atores se apresentam, no qual está o cenário, o figurino, o jogo de luzes e todos os elementos necessários para construção desse espetáculo. Esse processo de enlaçamento possibilita a construção de uma cenografia discursiva, sendo ao mesmo tempo fonte do discurso e aquilo que ele produz, pois, enunciar não é apenas acionar as normas de uma instituição de fala prévia, mas construir sobre essa base uma forma singular de enunciação (MAINGUENEAU, 2015), 
sendo o discurso jurídico um palco excelente para defesa de teses.

Como se percebe, no discurso jurídico, os lugares enunciativos vão se reproduzindo com a introdução de novas cenas e, consequentemente, de novos enunciados e enunciações que procuram se legitimar pelos argumentos de cada enunciador. "A cenografia legitima a situação de enunciação e estabelece as relações de tempo e espaço, além das condições necessárias para a constituição da imagem do enunciador" (OLIVEIRA, 2011, p. 36). Os lugares enunciativos de onde os sujeitos do discurso falam e fazem com que uma sequência discursiva se apresente de maneiras diversas, mas na sessão de mediação, isso não ocorre, já que os discursos vão sendo produzidos no momento oportuno, de cada parte envolvida no procedimento, respeitando o tempo de fala de cada um, seguindo um ritual. Além disso,

É importante ressaltar que o ritual determina ao sujeito que fala papéis sociais preestabelecidos. Demarca, também, o papel social daquele a quem o sujeito se dirige. No ritual, entra em jogo a questão dos enunciados verbovisuais ou sincréticos, isto é, o discurso se manifesta não apenas por meio de signos da linguagem verbal, mas também da linguagem não verbal, que engloba desde as expressões gestuais e faciais até a indumentária, a proxêmica, o habitus e o ethos (PIRIS e CERQUEIRA, 2013, p. 62).

Nesse sentido, esses rituais definem os gestos, comportamentos e as circunstâncias que constroem a cena de enunciação de um discurso, considerando o espaço de interação e interpelação dos sujeitos, em que cada um apresenta seu ponto de vista, privilegiando a relação intersubjetiva. A Mediação de Conflitos, como instituto jurídico, construiu regras flexíveis, mas definidas e estabelecidas em lei, orientadas pelo Manual de Conciliação Judicial (no procedimento extrajudicial, inclusive), do Conselho Nacional de Justiça. A cenografia da mediação, de acordo com as regras que permeiam a sessão, busca uma aproximação dos sujeitos, ainda que subordinados a uma determinada ordem do discurso. Para uma melhor visualização da aplicação prática de como melhor organizar a posição das partes durante a mediação e como é composta a cena: 


\section{A mesa redonda}

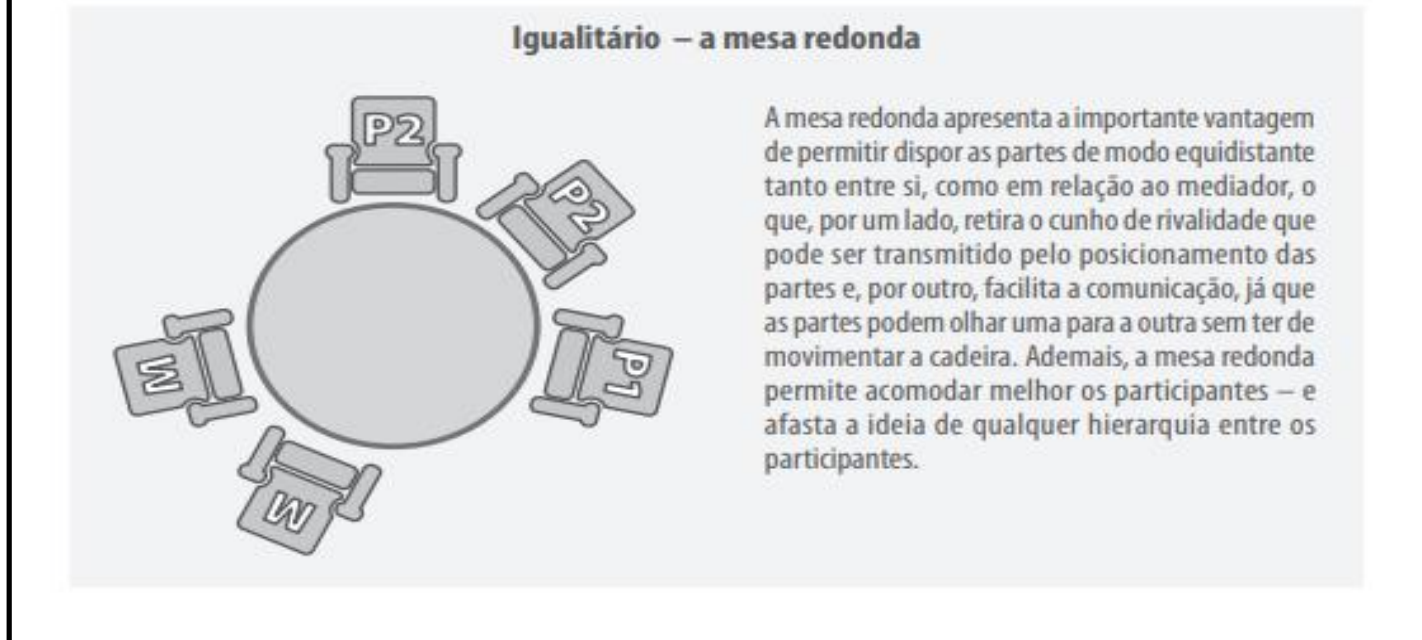

(Manual de Mediação Judicial, CNJ, 2016)

Conforme demonstra a figura acima, numa sessão de mediação, é recomendável que o posicionamento das partes seja realizado de modo que todos consigam ver e ouvir uns aos outros, como também participar dos debates. Uma segunda observação diz respeito à necessidade de se afastar qualquer aspecto que possa transparecer alguma hostilidade entre as partes. Assim sendo, de preferência, as partes devem se sentar em posições não antagônicas (opostas). O quadro enunciativo, proposto neste trecho, estabelece as posições físicas e enunciativas, as partes permanecem lado a lado e o mediador se posiciona de frente para facilitar a comunicação entre elas. Um dos objetivos da mediação é tentar evitar um sentimento de rivalidade ou polarização, o que, no caso da disposição das mesas, é melhor conseguido ao não colocar as partes de frente uma para a outra, mas, sim, lado a lado, no caso de mesa circular. Além disso, deve-se frisar que as pessoas que representam uma parte, ou se estiverem acompanhadas de advogados, devem conseguir se sentar juntamente com ela, caso assim desejarem (MANUAL CNJ, 2016).

\section{METODOLOGIA}

O material bibliográfico que constitui o corpus desta pesquisa é o relato de um caso envolvendo conflitos familiares, publicado no livro "Mediare: um guia prático para mediadores" de Lília Maia de Moraes Sales, já na sua terceira edição, que relata casos 
analisados pela autora, sob a perspectiva da Mediação de Conflitos como instituto jurídico. A obra, numa linguagem clara e objetiva orienta a formação de mediadores extrajudiciais, divulgando e capacitando pessoas, levando-as à assimilação dos discursos e experiências vivenciadas no cotidiano de mediadora, nas Casas de Mediação Comunitária, em Fortaleza.

A abordagem da pesquisa é qualitativa, haja vista a interpretação e análise direta do fenômeno e exploratória, visando uma maior familiaridade do pesquisador com o tema. Serão utilizados exemplos reais para explicar o fenômeno, em um cenário onde possa ser demonstrada a aplicação prática do instituto jurídico da mediação de conflitos como forma de melhorar a prestação jurisdicional.

\section{DISCUSSÃO E ANÁLISE}

Por se tratar de uma narrativa que descreve uma sessão de mediação, a autora recupera uma história já ocorrida, presenciada e marcada na sua memória. Esse lugar de fala do enunciador, demarca toda cena enunciativa, num mesmo ambiente, mudando os integrantes, levado por uma possibilidade de interpretação e análise. O que valida esta cena enunciativa está registrada nesse relato, documentado num livro, que recupera e estuda a ação dos personagens, permite avaliar o posicionamento dos coenunciadores. Temos um quadro cênico responsável pela legitimidade do dizer, pois se trata de ambiente jurídico, cuja cenografia busca a adesão das partes a crerem no que está sendo firmado.

Depois de muita conversa (mais de duas horas) e muita emoção, percebeu-se que Maria ainda gostava muito de João e que estava disposta a continuar o casamento desde que ele mudasse suas atitudes. João, por sua vez, admitiu que não queria perder Maria, que gostava muito dela e que iria mudar seu comportamento. Naquele momento, Maria estava disposta a perdoar o que se passou, e ele prometeu deixar de beber e procurar acompanhamento profissional.

(SALES, 2010, p. 102)

De acordo com o que foi exposto pela narrativa, podemos realizar uma leitura interpretativa. Nesse recorte, da determinação do tempo pela marca temporal mais de duas horas, podemos inferir pelos trechos de fala do enunciadores o desejo de preservarem as relações familiares, acrescentando novas razões que fortalecem os 
argumentos de ambos. Notamos a presença do discurso familiar em "Maria ainda gostava muito de João e que estava disposta a continuar o casamento desde que ele mudasse suas atitudes" e "Maria estava disposta a perdoar". Em relação ao discurso social, percebemos "ele prometeu deixar de beber e procurar acompanhamento profissional" mobilizando papéis sociodiscursivos, cujos temas provocam a reflexão por meio de suas marcas subjetivas produzidas pela linguagem, mobilizando efeitos de sentidos.

O mediador deve estar atento para as contradições e para fazer com que as pessoas falem e percebam o que é realmente verdade, com base no que já foi vivido entre elas. A confiança no mediador é muito importante, tanto que o constrangimento de conversar sobre a vida do casal desapareceu, e muito foi falado, inclusive sobre questões sexuais que os preocupavam e que nunca haviam sido faladas antes. Ou seja, 17 anos de casados e questões relacionadas à vida íntima do casal somente foram conversadas com o auxilio de um terceiro. Percebe-se como as pessoas passam a confiar no mediador. Essa confiança depende da forma como o mediador conduz a sessão.

(SALES, 2010, p. 103)

Aqui, a cena enunciativa é construída no intuito de declarar que o Centro de Mediação é uma instituição que agrega as pessoas, que aceita as diferenças e é um local em que espaço para o diálogo no âmbito dessa diversidade de conflitos. Embora a linguagem jurídica se caracterize pelas particularidades, no que tange ao aspecto lexical e às escolhas das marcas linguísticas, o mediador deve fazer uso de expressões pertencentes a qualquer falante da língua portuguesa, ainda que nesse contexto jurídico ganhe traços específicos. Na Mediação, podemos verificar que o procedimento é essencialmente argumentativo, em que as partes devem ser convincentes, já que as provas são retóricas. A argumentação aqui é vista como um fio condutor em busca da verdade e em busca do acordo, sugere um consenso, um ideal comum.

Observe-se que, no início da conversa, ela diz que o marido não tem consideração por ninguém, e depois afirma que ele é uma pessoa boa, que possui muitos amigos. Da mesma maneira, João afirma que Maria o odeia pelo fato de ela ter levado o caso ao Centro de Mediação. Ao longo da conversa, ele diz inúmeras vezes que ela sempre cuidou dele, sempre lhe deu muito carinho.

(SALES, 2010, p. 103) 
A cena narrada foi construída buscando evidenciar o posicionamento dos enunciadores e traz um recorte com trechos que demonstram conflitos, como "no início da conversa, ela diz que o marido não tem consideração por ninguém, e depois afirma que ele é uma pessoa boa", demonstrando posições contrárias. Ao observar o fragmento "ele diz inúmeras vezes que ela sempre cuidou dele", como o discurso funciona e como são mobilizados os recursos linguísticos e extralinguísticos, para que assim, os sentidos sejam produzidos e captados de maneira eficiente, pois é através da linguagem que se torna possível observar como são construídas as relações humanas. Nesse sentido, é possível notar que é na cenografia que ocorre a interação entre os interlocutores e, por meio do próprio discurso, é construída a discursivização dos fatos que, produzindo sentidos e acaba revelando os posicionamentos ideológicos dos enunciadores.

\section{CONSIDERAÇÕES FINAIS}

Com advento da Lei de Mediação foi uma grande conquista para os jurisdicionados, uma vez que ela disponibiliza ferramentas adequadas e humanizadas de resolução de conflitos. A mediação de conflitos surge para tentar prevenir e solucionar conflitos que ocorram nas interações sociais. Trata-se de uma ferramenta que pode levar a uma solução construtiva do conflito, em um cenário onde possa ser demonstrada a aplicação prática do instituto jurídico da mediação de conflitos como forma de melhorar a prestação jurisdicional, pois os mediandos podem fazer valer seus pontos de vista para com o Estado falarem.

Diante de todas essas afirmativas conclui-se que uma boa mediação pode efetivamente conduzir um discurso conjunto a um consenso, influenciando indiretamente os representantes de uma causa beneficiando todas as partes, ao mesmo tempo que legitima o bom desempenho do mediador, respeitando a necessidade de cada mediando, para que um não se beneficie à custa do outro. No tocante à cena enunciativa, consideramos que a cena englobante é o tipo de discurso a que pertence determinado enunciado que, no presente caso, é jurídico. Consideramos a sessão de mediação como cena englobante, o relato de sessões de mediação de conflitos familiares como cena genérica, num processo de enlaçamento que possibilita a construção de uma cenografia que é construída de acordo com aquilo que o discurso diz. 


\section{REFERÊNCIAS}

BRASIL, CONSELHO NACIONAL DE JUSTIÇA. Azevedo, André Gomma de (Org.). Manual de Mediação Judicial. 6 ed. Brasília/DF: CNJ, 2016.

BRASIL, Lei $n^{\circ}$ 13.105, de 16 de março de 2015. Disponível em:

http://www.planalto.gov.br/ccivil 03/ ato2015-2018/2015/lei/l13105.htm. Acesso em: 07 set 2019.

BRASIL, Lei $n^{\circ} 13.140$, de 26 de junho de 2015. Disponível em:

http://www.planalto.gov.br/ccivil_03/_ato2015-2018/2015/Lei/L13140.htm. Acesso em: 07 set 2019.

DORTIER, Jean-François. Dicionário de ciências humanas. São Paulo: Martins Fontes, 2010.

FERREIRA, Cristiane da Silva. Ethos discursivo e cenas de enunciação em letras de música raiz. 2008. Dissertação (Mestrado em Língua portuguesa). Pontifícia Universidade Católica de São Paulo, PUC, São Paulo-SP.

FOUCAULT, Michel. A ordem do discurso: aula inaugural no Collège de France, pronunciada em 2 de dezembro de 1970. Tradução de Laura Fraga de Almeida Sampaio. São Paulo: Edições Loyola, 2012.

MAINGUENEAU, D. \& CHARAUDEAU, P. Dicionário de Análise do Discurso. São Paulo: Contexto, 2003.

MAINGUENEAU, Dominique. Novas tendências em análise do discurso. 3 ed. Campinas: Pontes Editora Unicamp, 1997.

MAINGUENEAU, Dominique. Discurso e análise do discurso. São Paulo. Parábola editorial, 2015.

OLIVEIRA, Adriana Aparecida de. Cenas de enunciação e ethos discursivo no discurso literário escrito por Moacyr Scliar em Língua Portuguesa. 2011. Dissertação (Mestrado em Língua Portuguesa). Pontifícia Universidade Católica de São Paulo, PUC, São PauloSP.

SALES, Lília Maia de Morais. Mediare: um guia prático para mediadores. Rio de Janeiro: GZ, 2010. 